\title{
Determinants of Willingness of Patients with Type 2 Diabetes Mellitus to Receive the Seasonal Influenza Vaccine in Southeast China
}

\author{
Wei Feng ${ }^{1}$, Jun Cui ${ }^{2}$ and Hui Li $^{2, *}$ \\ 1 Department of Chronic Diseases and Community Health, Fenghua District Center for Disease Control and \\ Prevention, Ningbo 315000, Zhejiang, China; fhcdc01@126.com \\ 2 Department of Chronic Disease Prevention, Ningbo Municipal Center for Disease Control and Prevention, \\ Ningbo 315000, Zhejiang, China; swy_cyq@163.com \\ * Correspondence: lihui4329@163.com; Tel.: +86-574-87274542
}

Received: 1 April 2019; Accepted: 10 May 2019; Published: 21 June 2019

\begin{abstract}
Willingness of patients with Type 2 diabetes mellitus (T2DM) to receive the seasonal influenza vaccine is low in China. A cross-sectional study on a representative sample of T2DM patients was conducted in Ningbo, a city in southeast China, to assess T2DM patients' willingness to be vaccinated against influenza and identify the influence factors of this willingness. Data regarding the participant's history of influenza, the knowledge, willingness and uptake of the influenza vaccine, demographic characteristics, reasons for willingness or unwillingness to be vaccinated was collected. Only $19.55 \%$ of a total of 1749 participants reported a willingness to be vaccinated. Factors positively associated with willingness to be vaccinated were perceived susceptibility to influenza $(\mathrm{OR}=1.9$, $95 \%$ CI: 1.5-2.5), awareness of the vaccine ( $\mathrm{OR}=1.7,95 \% \mathrm{CI}: 1.3-2.3)$ and previous history of influenza vaccination $(\mathrm{OR}=4.4,95 \% \mathrm{CI}$ : 3.0-6.4). Patients with T2DM who were farmers $(\mathrm{OR}=0.6,95 \% \mathrm{CI}$ : $0.4-0.8$ ) and those managed by contracted family doctors (OR $=0.8,95 \%$ CI: 0.6-1.0) expressed less willingness to be vaccinated. Targeted interventions such as enhancing health education and strengthening medical staff training should be conducted to increase T2DM patients' willingness to be vaccinated and enhance influenza vaccine uptake among this population.
\end{abstract}

Keywords: determinants; diabetic patients; seasonal influenza vaccine; willingness

\section{Introduction}

Influenza, a common acute respiratory infection, has become a major public health problem worldwide [1,2]. Evidence from the World Health Organisation (WHO) shows that influenza causes 3-5 million serious illnesses annually [3]. Patients with Type 2 Diabetes Mellitus(T2DM) are generally susceptible to influenza and some also have a metabolic syndrome or cardiovascular disease $[4,5]$, which results in a higher risk of hospitalisation or death due to influenza infection than for healthy individuals [6,7]. In recent years, the prevalence of diabetes has increased rapidly in China from $2.5 \%$ in 1994 to $10.9 \%$ in 2013, which means that the number of patients with T2DM in the country has reached an estimated 150 million [8,9]. Therefore, patients with T2DM are a key group that we should target for influenza prevention.

Currently, one of the most effective measures to prevent influenza in patients with T2DM is to receive a seasonal influenza vaccine. Several studies have identified influenza vaccination as an essential method to reduce the incidence of influenza complications, including influenza-related hospitalisation and death [10-13]. Furthermore, both domestic and international guidelines recommend influenza vaccines for people with T2DM [14-18]. The influenza vaccination rate among patients with T2DM reported in China ranged from $2.9 \%$ to $28.8 \%$ and community-based interventions could 
significantly increase coverage of influenza vaccine [19-21]. Similar result was discovered in Ningbo: the vaccination rate among 1682 patients with T2DM reached $80.0 \%$ after adopting community interventions in Dongqianhu Town. However, monitoring results showed a low influenza vaccination rate of only $6.0 \%$ among patients with T2DM in non-Dongqianhu Town areas of Ningbo City in 2017. In order to improve the influenza vaccine uptake, primary care physicians in Ningbo City are required to recommend vaccination to patients with T2DM. With the aim of providing a basis for improving future influenza vaccination coverage in this population, our study explored the willingness to receive the influenza vaccine and their influencing factors among patients with T2DM in Ningbo City.

\section{Materials and Methods}

\subsection{Study Area}

Ningbo is a developed city in southeast China with 10 districts and counties and approximately 8.5 million permanent residents. A total number of 240,343 patients in the city attend a free, government-provided diabetes health management program, which was a program offered under the Chinese basic public health service. The program included blood glucose monitoring, health education, lifestyle intervention, health examination, and treatment of diseases for patients aged over 35 with T2DM.

\subsection{Study Design and Sampling Method}

This cross-sectional study targeted patients with T2DM attending the diabetes health management program in Ningbo City from December 2016 to January 2017. The minimum sample size was determined to be 1536 by using a sample size formula. Considering that some patients might refuse to visit the programme, the sample size was expanded by $10 \%$, thus resulting in a final target sample of 1690 individuals.

We used a two-stage sampling method to select research subjects. First, two towns were randomly selected in each of nine counties or districts; one district was excluded because a similar investigation had previously been conducted there. Next, 100 patients with T2DM attending the diabetes health management program in each designated town were randomly selected as research participants. Eventually, a total of 1800 patients with T2DM were invited to participate in our survey, 1784 of them agreed and 1749 subjects completed the questionnaires with response rate of $97.17 \%$. The top two reasons for non-completion of the questionnaire were that 35 subjects refused to answer some questions included in the questionnaire and 16 subjects refused to participate in our investigation.

\subsection{Ethics Statement}

The Ethics Committee of the Ningbo Municipal Center for Disease Control and Prevention approved this research (No.201811). Oral consent was obtained from all participants before their inclusion in the study and participation was anonymous.

\subsection{Data Collection}

Data was collected from selected patients with T2DM through face-to-face interviews by trained investigators. The interview questionnaire consisted of four sections and a total of 34 questions. Section one included 11 questions regarding the subject's history of influenza and the knowledge of the influenza. Section two contained 6 questions about the participants' perception of the influenza vaccine. In section three, 7 questions were used to assess the participants' willingness and uptake of the influenza vaccine. In section four, the participants were asked 10 questions about their demographic characteristics. Most of the questions, such as participants' knowledge, willingness and practice of influenza vaccine were single-choice. The permissible response options were $1=$ "yes", 2 = "no", $99=$ "unclear". Few questions like reasons for willingness or unwillingness to receive influenza 
vaccines were multiple choice. The permissible response options ranged from 1 to 9 ; the details are displayed in Table 2.

\subsection{Statistical Analysis}

All data were entered using EpiData 3.0 (Odense, Denmark) and analysed applying SPSS Version 13.0 (SPSS Inc., Chicago, IL, USA). Descriptive statistics like frequency and percentages were calculated for categorical variables. A multivariable logistic regression analysis was utilised and odds ratio with a $95 \%$ confidence interval ( $95 \%$ CIs) were computed to identify determinants of willingness among patients with T2DM to receive the seasonal influenza vaccine. A two-tailed $p$ value $<0.05$ was judged as statistically significant.

\section{Results}

\subsection{Sociodemographic Characteristics of Study Participants}

A total of 1800 patients with T2DM were invited for our study; 1784 of them agreed and 1749 participants completed the questionnaires. Among all included subjects, 1351 (77.2\%) were aged over 60, 1076 (61.5\%) were females, $956(54.7 \%)$ were from urban areas, and $898(51.3 \%)$ were farmers. Approximately three-fourths (75.3\%) of the participants earned a monthly income of less than 3000 yuan, and the proportion of patients with T2DM receiving management from a contracted family doctor was $63.0 \%$. Sociodemographic characteristics of the recruited participants are displayed in Table 1.

Table 1. Sociodemographic characteristics of study participants $(\mathrm{N}=1749)$.

\begin{tabular}{|c|c|c|}
\hline Variable & Participants & Proportion $(\%)$ \\
\hline \multicolumn{3}{|l|}{ Age(years) } \\
\hline$<60$ & 398 & 22.8 \\
\hline$\geq 60$ & 1351 & 77.2 \\
\hline \multicolumn{3}{|l|}{ Gender } \\
\hline Male & 673 & 38.5 \\
\hline Female & 1076 & 61.5 \\
\hline \multicolumn{3}{|l|}{ Region } \\
\hline Urban & 956 & 54.7 \\
\hline Rural & 793 & 45.3 \\
\hline \multicolumn{3}{|l|}{ Occupation } \\
\hline Farmer & 898 & 51.3 \\
\hline Others & 851 & 48.7 \\
\hline \multicolumn{3}{|l|}{ Educational Level } \\
\hline Primary School or Below & 1167 & 66.7 \\
\hline Junior-senior High School or Above & 582 & 33.3 \\
\hline \multicolumn{3}{|l|}{ Marital status } \\
\hline Married & 1509 & 86.3 \\
\hline Divorce or others & 240 & 13.7 \\
\hline \multicolumn{3}{|l|}{ Monthly income } \\
\hline$<3000 ¥$ & 1317 & 75.3 \\
\hline$\geq 3000 ¥$ & 432 & 24.7 \\
\hline \multicolumn{3}{|l|}{ Management by contracted family doctor } \\
\hline No & 647 & 37.0 \\
\hline Yes & 1102 & 63.0 \\
\hline
\end{tabular}


3.2. Reasons for Willingness and Unwillingness to Receive Seasonal Influenza Vaccination among Patients with $T 2 D M$

Among the 1749 participants, 342 (19.6\%) expressed a willingness to receive the influenza vaccine and $169(9.7 \%)$ participants reported having been previously vaccinated. Reasons for willingness or unwillingness among patients with T2DM to receive the seasonal influenza vaccine are presented in Table 2. The top three reasons reported among 342 willing participants were the vaccine's effectiveness in reducing the risk of influenza (68.4\%), belief in the safety and reliability of vaccines $(30.4 \%)$, and the free cost or full reimbursement by their medical insurers (27.8\%). In contrast, feeling in good health with no need for vaccinations (36.2\%), fear of adverse reactions $(19.0 \%)$, and the high cost of vaccines $(17.1 \%)$ were the most commonly reported reasons among 1407 unwilling respondents.

Table 2. Reasons for willingness and unwillingness among patients with T2DM to receive seasonal influenza vaccination (multiple choice).

\begin{tabular}{lccllc}
\hline $\begin{array}{l}\text { Reasons for willingness to be vaccinated } \\
\text { against influenza }\end{array}$ & $\mathrm{N}$ & $\%$ & $\begin{array}{l}\text { Reasons for unwillingness to be vaccinated } \\
\text { against influenza }\end{array}$ & $\mathrm{N}$ & $\%$ \\
\hline $\begin{array}{l}\text { Effectiveness of the vaccine to reduce the risk } \\
\text { of influenza }\end{array}$ & 234 & 68.4 & In good health with no need for vaccination & 509 & 36.2 \\
\hline Safe and reliable vaccines & 104 & 30.4 & Fear of adverse reactions & 267 & 19.0 \\
\hline $\begin{array}{l}\text { Free charge or full reimbursement by } \\
\text { medical insurance }\end{array}$ & 95 & 27.8 & High cost of vaccines & 241 & 17.1 \\
\hline Feelings of susceptibility to influenza & 90 & 26.3 & Poor effect of influenza vaccine & 104 & 7.4 \\
\hline Doctor's advice & 83 & 24.2 & No advice from doctors & 96 & 6.8 \\
\hline Friends' or family members' advice & 27 & 7.9 & Inconvenient vaccination & 92 & 6.5 \\
\hline Suffered from influenza last year & 18 & 5.3 & $\begin{array}{l}\text { No knowledge of the time or place } \\
\text { of vaccination }\end{array}$ & 68 & 4.8 \\
\hline Other & 4 & 1.2 & Other & 49 & 3.5 \\
\hline
\end{tabular}

3.3. Factors Associated with the Willingness to Receive the Seasonal Influenza Vaccine among Patients with $T 2 D M$

Table 3 presents the results of the multivariable logistic regression analysis of factors influencing T2DM patients' willingness to receive the seasonal influenza vaccine. After controlling for other confounding factors, perceived susceptibility to influenza, awareness of the influenza vaccine and previous history of influenza vaccination were positively correlated with the willingness to receive the vaccine. Conversely, the farming occupation and being managed by a contracted family doctor were negatively associated with T2DM patients' willingness to be vaccinated against influenza. 
Table 3. Multivariable logistic regression analysis for influential factors associated with T2DM patients' willingness to receive seasonal influenza vaccination.

\begin{tabular}{|c|c|c|c|c|c|}
\hline \multicolumn{2}{|l|}{ Characteristic } & \multirow{3}{*}{$\begin{array}{c}\begin{array}{c}\text { Willingness to be Vaccinated } \\
\text { No (\%) }\end{array} \\
194(18.0) \\
148(22.0)\end{array}$} & \multirow{3}{*}{$\begin{array}{c}\begin{array}{c}\text { Unwillingness to be Vaccinated } \\
\text { No (\%) }\end{array} \\
882(82.0) \\
525(78.0)\end{array}$} & \multirow{3}{*}{$\begin{array}{c}\text { OR }(95 \% \mathrm{CI}) \\
1 \\
1.1(0.9-1.5)\end{array}$} & \multirow{3}{*}{$\begin{array}{c}P \text { Value } \\
0.34\end{array}$} \\
\hline Gender & Female & & & & \\
\hline & Male & & & & \\
\hline \multirow[t]{2}{*}{ Region } & Rural & $130(16.4)$ & $663(83.610)$ & 1 & \\
\hline & Urban & $212(22.2)$ & $744(77.8)$ & $1.2(0.9-1.6)$ & 0.12 \\
\hline \multirow{2}{*}{ Occupation } & Others & $207(24.3)$ & $644(75.7)$ & 1 & \\
\hline & Farmer & $135(15.0)$ & $763(85.0)$ & $0.6(0.4-0.8)$ & $<0.01$ \\
\hline \multirow{2}{*}{ Educational level } & Primary school or below & $211(18.1)$ & $956(81.9)$ & 1 & \\
\hline & Junior-senior high school or above & $131(22.5)$ & $451(77.5)$ & $1.1(0.8-1.6)$ & 0.42 \\
\hline \multirow[t]{2}{*}{ Age } & $<60$ & $64(16.1)$ & $334(83.9)$ & 1 & \\
\hline & $\geq 60$ & $278(20.6)$ & $1073(79.4)$ & $1.4(1.0-1.9)$ & 0.06 \\
\hline \multirow[t]{2}{*}{ Management by contracted family doctor } & No & $131(20.2)$ & $516(79.8)$ & 1 & \\
\hline & Yes & $211(19.2)$ & $891(80.8)$ & $0.8(0.6-1.0)$ & 0.04 \\
\hline \multirow[t]{2}{*}{ Marital status } & Divorced or other & $44(18.3)$ & $196(81.7)$ & 1 & \\
\hline & Married & $298(19.8)$ & $1211(80.2)$ & $1.1(0.8-1.7)$ & 0.49 \\
\hline \multirow[t]{2}{*}{ Monthly income } & $<3000 ¥$ & $245(18.6)$ & $1072(81.4)$ & 1 & \\
\hline & $\geq 3000 ¥$ & $97(22.5)$ & $335(77.5)$ & $1.3(0.9-1.8)$ & 0.17 \\
\hline \multirow[t]{2}{*}{ Previous history of influenza vaccination } & No & $251(15.9)$ & $1329(84.1)$ & 1 & \\
\hline & Yes & $91(53.8)$ & $78(46.2)$ & $4.4(3.0-6.4)$ & $<0.01$ \\
\hline \multirow[t]{2}{*}{ Perceived susceptibility to influenza } & No & $218(16.3)$ & $1120(83.7)$ & 1 & \\
\hline & Yes & $124(30.2)$ & $287(69.8)$ & $1.9(1.5-2.5)$ & $<0.01$ \\
\hline \multirow[t]{2}{*}{ Awareness of influenza vaccine } & No & $138(13.6)$ & $876(86.4)$ & 1 & \\
\hline & Yes & $204(27.8)$ & $531(72.2)$ & $1.7(1.3-2.3)$ & $<0.01$ \\
\hline \multirow[t]{2}{*}{ Awareness of vaccination reimbursement policy } & No & $288(18.4)$ & 1273 (81.6) & 1 & \\
\hline & Yes & 54 (28.7) & 134 (71.3) & $1.2(0.8-1.7)$ & 0.48 \\
\hline
\end{tabular}




\section{Discussion}

In the present study, it was found that less than $20 \%$ of patients with T2DM were willing to be vaccinated against influenza, which was significantly lower than that observed in the Chinese city of ShenZhen [19]. The proportion of participants who had received the vaccine was even lower at slightly under $10 \%$. Influenza vaccination rates in Ningbo City are significantly lower than those reported in the Netherlands (74.8\%) [22], Spain (65.7\%) [23], Saudi Arabia (61.2\%) [24], and South Korea (50.0\%) [25]. In Ningbo City, influenza vaccination rates among patients with T2DM only in Dongqianhu Town exceeded $75 \%$. Consequently, there is a need to carry out targeted interventions to increase the willingness of diabetic patients in Ningbo to be vaccinated and eventually improve the poor vaccination status for influenza among this population.

Our study revealed that the effectiveness of the vaccine to reduce the risk of influenza is the most important factor influencing the willingness of patients with T2DM to be vaccinated. A systematic review published in 2018 indicated that influenza vaccination reduced the risk of hospitalisation and death in patients with T2DM and the cost of hospitalisation was \$1283 lower for participants in the vaccination group than for those in the non-vaccination group [11]. There have been several guidelines recommending influenza vaccination for patients with T2DM [14-18], and many countries have incorporated influenza vaccines into their national immunisation plans [26]. An assessment of the cost-effectiveness of influenza vaccination for patients with T2DM in Turkey demonstrated that an increase in the vaccination rate from $9.1 \%$ to $20 \%$ was cost-effective according to WHO guidelines [27]. In accordance with the recognition of its benefits for patients with T2DM, the city of Ningbo began in 2016 to promote the influenza vaccine for this population.

In our study, self-identification as being in good physical condition and fear of vaccines' side effects were the two most common reasons why patients with T2DM were reluctant to receive influenza vaccines. This result is consistent with other findings [28,29], and it suggests that some patients with T2DM lack an understanding of the vaccine and have a low awareness of the benefits of influenza vaccination. The supposed high price of vaccines was another commonly-cited reason for T2DM patients' unwillingness. In 2014, a policy was issued in Ningbo that personal health insurance accounts could be used to reimburse the cost of influenza vaccination for individuals and their families; however, many patients with T2DM remain unaware of this policy. Therefore, medical staff should take advantage of the time spent with patients during visits and follow-ups to carry out targeted health education as a means to promote the vaccine and spread knowledge of the regional reimbursement policy.

Previous studies have demonstrated that recommendations by medical staff are a significant factor in increasing influenza vaccination coverage [30-32]. Conversely, in our study, a negative correlation was revealed between management by contracted family doctors and patients' willingness to be vaccinated, thus indicating a need for family doctors to play a more active role in promoting influenza vaccination among patients with T2DM. The results of a recent survey in Ningbo on whether medical personnel were willing to recommend influenza vaccines to patients with T2DM showed such willingness among only $58.13 \%$ of the respondents [33]. However, the proportion of clinicians with a willingness to make such recommendations might be even lower in practice, which might be related to several factors. Firstly, doctors in China are heavily burdened in that they provide outpatient services for a large number of patients daily. Due to time limitations, doctors do not have many opportunities to recommend influenza vaccines to patients with T2DM. Secondly, the concept of disease prevention has not yet been fully established among local clinicians; thus, many medical personnel are primarily concerned with disease treatment and are relatively ignorant of the benefits of recommending influenza vaccines to patients with T2DM. Thirdly, concerns regarding possible side-effects make some medical personnel reluctant to recommend the influenza vaccine to patients with T2DM. Strengthening the training of medical staff, particularly family doctors, is a means to address this situation. In addition, there is a need to gradually increase the number of medical staff to reduce their burden and provide them with sufficient time to recommend influenza vaccine to patients with T2DM. 
Compared with other occupations, farmers are more reluctant to be vaccinated against influenza, which might be attributable to their long-term physical work and self-evaluation of being in good physical condition. However, the low health literacy of farmers and insufficient medical resources in rural areas might also result in their lower willingness to receive vaccination. Accordingly, related health education and interventions for farmers should be strengthened.

Other studies have identified a history of prior influenza vaccination as a positive predictor of T2DM patients' willingness to repeat the experience [34-37]. Our findings align with those results, as a previous history of influenza vaccination had the highest OR value (4.41) among all factors that were positively related to T2DM patients' willingness to be vaccinated. In addition, we observed a positive correlation between T2DM patients' feelings of susceptibility to influenza and their willingness to be vaccinated, which was also consistent with previous findings [38]. Patients with T2DM who are consciously susceptible to influenza not only have greater knowledge of the disease, but also pay more attention to their own physical condition, thus resulting in a relatively higher willingness to be vaccinated.

Our study has several limitations. Firstly, causal relationships are impossible to determine due to the study's cross-sectional design. Secondly, the subjects of this study were limited to patients with T2DM participating in a diabetes health management program; thus, the findings cannot claim to be representative of all diabetics. Thirdly, recall bias is an inevitable factor, as some indicators reflect information remembered from the past year or earlier, which might influence the percentage of factors associated with T2DM patients' willingness in our study. Fourth, this article focuses only on T2DM patients' willingness to receive the influenza vaccination; however, a willingness to be vaccinated does not necessarily lead to the actual practice of vaccination. Further study is warranted to explore the vaccination situation of patients with T2DM who are willing to receive the influenza vaccine.

\section{Conclusions}

This study found a low proportion of patients with T2DM who were willing to be vaccinated against influenza. Self-evaluations of good physical condition, fear of adverse reactions, and the perceived high cost of vaccines were the main barriers to vaccination, whereas perceived susceptibility to influenza, awareness of the vaccine, and a previous history of influenza vaccination increased T2DM patients' willingness to be vaccinated. T2DM patients who were farmers and those being managed by family doctors expressed less willingness to be vaccinated. Targeted interventions such as enhancing health education for diabetic patients and strengthening the training of medical personnel should be conducted to effectively promote influenza vaccination among diabetic patients.

Author Contributions: H.L. designed the study and revised the manuscript. W.F. analysed the data and drafted the manuscript. J.C. collected and screened the data. All authors read and approved the final manuscript.

Funding: This study was supported by a pilot project on chronic disease and immune prevention policy research by the Chinese Preventive Medicine Association (20170106), the Chinese Preventive Medicine Association's 'Effectiveness Evaluation and Cost-Benefit Analysis of Influenza Vaccination in Community Managed Diabetic Patients' project and the opening foundation of the Key Laboratory of Prevention and Control of Infectious Diseases and Vaccines of Zhejiang Province.

Conflicts of Interest: The authors declare no conflict of interest.

\section{References}

1. Mortality, morbidity, and hospitalisations due to influenza lower respiratory tract infections, 2017: An analysis for the Global Burden of Disease Study 2017. Lancet Respir Med. 2019, 7, 69-89. [CrossRef]

2. World Health Organization. Up to 650000 People die of Respiratory Diseases Linked to Seasonal Flu each Year. Available online: http://apps.who.int/mediacentre/news/releases/2017/seasonal-flu/en/index.html (accessed on 19 December 2017).

3. World Health Organization. Influenza (Seasonal). Available online: https://www.who.int/zh/news-room/ fact-sheets/detail/influenza-(seasonal) (accessed on 31 March 2018). 
4. Jing, Y.; Hong, T.; Bi, Y.; Hu, D.; Chen, G.; Li, J.; Zhang, Y.; Zhang, R.; Ji, L.; Zhu, D. Prevalence, treatment patterns and control rates of metabolic syndrome in a Chinese diabetic population: China Cardiometabolic Registries 3B study. J. Diabetes Investig. 2018, 9, 789-798. [CrossRef] [PubMed]

5. Einarson, T.R.; Acs, A.; Ludwig, C.; Panton, U.H. Prevalence of cardiovascular disease in type 2 diabetes: A systematic literature review of scientific evidence from across the world in 2007-2017. Cardiovasc. Diabetol. 2018, 17, 83. [CrossRef] [PubMed]

6. Kornum, J.B.; Thomsen, R.W.; Riis, A.; Lervang, H.H.; Schønheyder, H.C.; Sørensen, H.T. Type 2 diabetes and pneumonia outcomes: A population-based cohort study. Diabetes Care 2007, 30, 2251-2257. [CrossRef] [PubMed]

7. Standards of medical care in diabetes-2015: Summary of revisions. Diabetes Care 2015, 38 (Suppl. S4). [CrossRef]

8. Pan, X.R.; Yang, W.Y.; Li, G.W.; Liu, J. Prevalence of diabetes and its risk factors in China, 1994. National Diabetes Prevention and Control Cooperative Group. Diabetes Care 1997, 20, 1664-1669. [CrossRef]

9. Wang, L.; Gao, P.; Zhang, M.; Huang, Z.; Zhang, D.; Deng, Q.; Li, Y.; Zhao, Z.; Qin, X.; Jin, D.; et al. Prevalence and Ethnic Pattern of Diabetes and Prediabetes in China in 2013. JAMA 2017, 317, 2515-2523. [CrossRef]

10. Casanova, L.; Cortaredona, S.; Gaudart, J.; Launay, O.; Vanhems, P.; Villani, P.; Verger, P. Effectiveness of seasonal influenza vaccination in patients with diabetes: protocol for a nested case-control study. BMJ Open 2017, 7, e016023. [CrossRef]

11. Dos, S.G.; Tahrat, H.; Bekkat-Berkani, R. Immunogenicity, safety, and effectiveness of seasonal influenza vaccination in patients with diabetes mellitus: A systematic review. Hum. Vaccin. Immunother. 2018, 14, 1853-1866.

12. Yang, L.; Nan, H.; Liang, J.; Chan, Y.H.; Chan, L.; Sum, R.W.; Kwan, Y.M.; Zhou, F.; Meng, H.; Suen, L.K. Influenza vaccination in older people with diabetes and their household contacts. Vaccine 2017, 35, 889-896. [CrossRef]

13. Vamos, E.P.; Pape, U.J.; Curcin, V.; Harris, M.J.; Valabhji, J.; Majeed, A.; Millett, C. Effectiveness of the influenza vaccine in preventing admission to hospital and death in people with type 2 diabetes. CMAJ 2016, 188, E342-E351. [CrossRef] [PubMed]

14. Grohskopf, L.A.; Sokolow, L.Z.; Broder, K.R.; Walter, E.B.; Fry, A.M.; Jernigan, D.B. Prevention and Control of Seasonal Influenza with Vaccines: Recommendations of the Advisory Committee on Immunization Practices-United States, 2018-19 Influenza Season. MMWR Recomm. Rep. 2018, 67, 1-20. [CrossRef] [PubMed]

15. Feng, L.Z.; Peng, Z.B.; Wang, D.Y.; Yang, P.; Yang, J.; Zhang, Y.Y.; Chen, J.; Jiang, S.Q.; Xu, L.L.; Kang, M.; et al. Technical guidelines for seasonal influenza vaccination in China, 2018-2019. Zhonghua Liu Xing Bing Xue Za Zhi 2018, 39, 1413-1425. (in Chinese). [PubMed]

16. World Health Organization. Vaccines against Influenza WHO Position Paper-November 2012. Available online: https://www.who.int/wer/2012/wer8747.pdf?ua=1/ (accessed on 23 November 2012).

17. Centers for Disease Control and Prevention. Flu and People with Diabetes. Available online: https://www.cdc.gov/flu/highrisk/diabetes.htm?CDC_AA_refVal=https\%3A\%2F\%2Fwww.cdc.gov\% 2Fflu\%2Fdiabetes\%2Findex.htm (accessed on 5 February 2019).

18. Chinese Diabetes Society. Guidelines for the Prevention and Treatment of Type 2 Diabetes in China (2017 edition). Chin. J. Diabetes Mellitus 2018, 10, 4-66.

19. Yuan, X.L.; Wang, R.; Fu, Y.; Xie, K.; Ni, W.Q.; Xu, J. The analysis of knowledge-attitude-practice (KAP) and influencing factors of influenza vaccination in type 2 diabetes mellitus (T2DM) patients. Chin. J. Prev. Contr. Chron. Dis. 2018, 26, 905-909.

20. Jiamg, C.Z.; Yuan, Y.R.; Sun, L.Y.; Dong, F. Survey on knowledge, attitude and practice of influenza vaccination in type 2 diabetes mellitus patients in urban communities. Prev. Med. 2017, 29, 1017-1020, 1023.

21. Tao, L.L.; Lu, M.; Wang, X.N.; Han, X.Y. Effectiveness of a community-based comprehensive intervention for influenza vaccination of diabetes patients. Chin. J. Vaccin. Immun. 2019, 25, 92-95.

22. Tacken, M.A.; Jansen, B.; Mulder, J.; Campbell, S.M.; Braspenning, J.C. Dutch influenza vaccination rate drops for fifth consecutive year. Vaccine 2015, 33, 4886-4891. [CrossRef]

23. Jiménez-Garcia, R.; Lopez-de-Andres, A.; Hernandez-Barrera, V.; Gómez-Campelo, P.; San, A.F.J.; de Burgos-Lunar, C.; Cárdenas-Valladolid, J.; Abánades-Herranz, J.C.; Salinero-Fort, M.A. Influenza vaccination in people with type 2 diabetes, coverage, predictors of uptake, and perceptions. Result of the MADIABETES cohort a 7years follow up study. Vaccine 2017, 35, 101-108. [CrossRef] 
24. Alnaheelah, I.M.; Awadalla, N.J.; Al-Musa, K.M.; Alsabaani, A.A.; Mahfouz, A.A. Influenza Vaccination in Type 2 Diabetes Patients: Coverage Status and Its Determinants in Southwestern Saudi Arabia. Int. J. Environ. Res. Public Health 2018, 15, 1381. [CrossRef]

25. Shin, H.Y.; Chung, J.H.; Hwang, H.J.; Kim, T.H. Factors influencing on influenza vaccination and its trends of coverage in patients with diabetes in Korea: A population-based cross-sectional study. Vaccine 2018, 36, 91-97. [CrossRef] [PubMed]

26. World Health Organization. Seasonal Influenza Vaccine Policy and Utilization: A Global Perspective. Available online: http://www.who.int/influenza_vaccines_plan/resources/hombach.pdf (accessed on 21 December 2015).

27. Akın, L.; Macabéo, B.; Caliskan, Z.; Altinel, S.; Satman, I. Cost-Effectiveness of Increasing Influenza Vaccination Coverage in Adults with Type 2 Diabetes in Turkey. PLoS ONE 2016, 11, e0157657. [CrossRef] [PubMed]

28. Verger, P.; Cortaredona, S.; Pulcini, C.; Casanova, L.; Peretti-Watel, P.; Launay, O. Characteristics of patients and physicians correlated with regular influenza vaccination in patients treated for type 2 diabetes: A follow-up study from 2008 to 2011 in southeastern France. Clin. Microbiol. Infect. 2015, 21, 930.e1-930.e9. [CrossRef] [PubMed]

29. Tan, E.K.; Lim, L.H.; Teoh, Y.L.; Ong, G.; Bock, H.L. Influenza and seasonal influenza vaccination among diabetics in Singapore: Knowledge, attitudes and practices. Singapore Med. J. 2010, 51, 623-630. [PubMed]

30. Giese, C.; Mereckiene, J.; Danis, K.; O’Donnell, J.; O'Flanagan, D.; Cotter, S. Low vaccination coverage for seasonal influenza and pneumococcal disease among adults at-risk and health care workers in Ireland, 2013: The key role of GPs in recommending vaccination. Vaccine 2016, 34, 3657-3662. [CrossRef] [PubMed]

31. Lv, M.; Fang, R.; Wu, J.; Pang, X.; Deng, Y.; Lei, T.; Xie, Z. The free vaccination policy of influenza in Beijing, China: The vaccine coverage and its associated factors. Vaccine 2016, 34, 2135-2140. [CrossRef] [PubMed]

32. Yi, B.; Zhou, S.; Song, Y.; Chen, E.; Lao, X.; Cai, J.; Greene, C.M.; Feng, L.; Zheng, J.; Yu, H.; et al. Innovations in adult influenza vaccination in China, 2014-2015: Leveraging a chronic disease management system in a community-based intervention. Hum. Vaccin. Immunother. 2018, 14, 947-951. [CrossRef] [PubMed]

33. Ye, L.; Chen, J.; Fang, T.; Cui, J.; Li, H.; Ma, R.; Sun, Y.; Li, P.; Dong, H.; Xu, G. Determinants of healthcare workers' willingness to recommend the seasonal influenza vaccine to diabetic patients: A cross-sectional survey in Ningbo. China Hum. Vaccin. Immunother. 2018, 1-8. [CrossRef] [PubMed]

34. Tsai, Y.Y.; Lee, J.J.; Hsieh, W.H. Determinants of the public intent to receive the seasonal influenza vaccine and protective behaviors: A population-based study in Taiwan. Vaccine 2014, 32, 6667-6675. [CrossRef]

35. Huang, J.H.; Miao, Y.Y.; Kuo, P.C. Pandemic influenza H1N1 vaccination intention: Psychosocial determinants and implications from a national survey, Taiwan. Eur. J. Public Health 2012, 22, 796-801. [CrossRef]

36. Mok, E.; Yeung, S.H.; Chan, M.F. Prevalence of influenza vaccination and correlates of intention to be vaccinated among Hong Kong Chinese. Public Health Nurs. 2006, 23, 506-515. [CrossRef] [PubMed]

37. Yi, S.; Nonaka, D.; Nomoto, M.; Kobayashi, J.; Mizoue, T. Predictors of the uptake of A (H1N1) influenza vaccine: findings from a population-based longitudinal study in Tokyo. PLoS ONE 2011, 6, e18893. [CrossRef] [PubMed]

38. Yu, D.S.; Low, L.P.; Lee, I.F.; Lee, D.T.; Ng, W.M. Predicting influenza vaccination intent among at-risk chinese older adults in Hong Kong. Nurs. Res. 2014, 63, 270-277. [CrossRef] [PubMed]

(C) 2019 by the authors. Licensee MDPI, Basel, Switzerland. This article is an open access article distributed under the terms and conditions of the Creative Commons Attribution (CC BY) license (http://creativecommons.org/licenses/by/4.0/). 